\title{
CIVIL SOCIETY ORGANISATIONS AND PUBLIC HEALTH RESEARCH - EVIDENCE FROM EIGHT EUROPEAN UNION NEW MEMBER STATES
}

\author{
Agnese Knabe ${ }^{1}$, Mark McCarthy² \\ 'Skalbes Foundation, Riga, Latvia \\ ${ }^{2}$ Department of Epidemiology and Public Health, University College London, UK
}

\section{SUMMARY}

Introduction: Civil society organisations (CSO) are not-for-profit, non-governmental organisations operating in the public interest. They are the "third sector" that is strongly developed in Western European countries, ensuring the link between citizens and government and working as a counterbalance to the business sector. Their role in support of public health research deserves attention.

Methods: Within a broader European study (STEPS - Strengthening Engagement in Public Health Research), public health organisations in eight European Union new member states (Cyprus, Estonia, Latvia, Lithuania, Malta, Romania, Slovakia, Slovenia) identified national CSOs with interests in health. A questionnaire was developed jointly, translated into national languages and sent by e-mail to 474 organisations, with 128 completed responses (27\%).

Results: Most CSOs would like to be more involved in setting or advising on public-health research policy, and greater collaboration between CSOs, professional organisations and governmental institutions. Respondents did not see CSOs directly doing research, but recommended mobilizing researchers and organsations, supporting research themes, and lobbying to use public health evidence in policy and decision-making. They could receive more education for, and discussion of, public health research, and offer support in applying for research funding.

Conclusion: Civil society organisations can contribute importantly in setting public health research agendas. Research commissioning should give greater recognition of this role, improve links between CSOs, researchers and governmental institutions, and develop a stronger shared basis for public health policy and practice.

Key words: research policy, Europe, public health, survey, civil society

Address for correspondence: M. McCarthy, Department of Epidemiology and Public Health, University College London, 1-19 Torrington Place, London WC1E 6BT, UK. E-mail: m.mccarthy@ucl.ac.uk

\section{INTRODUCTION}

The improvement of health in the population (the practice of public health) depends on the working of different agencies and individuals within society. Governmental and public sector organisations have traditionally taken the leading role, working both in environmental control and with clinical healthcare services. Where individual responsibilities and actions interact with governmental measures for protection and health promotion, the voices of society are important. Yet, while representative government provides a means of decision-making and leadership for majority political opinions, minorities are not so well served by democracies. To represent the range of views, legal and social means have developed for civil society organisations to supplement representation through government.

Civil society has a range of definitions and understandings, related to the democratic traditions of each country. In ancient Rome, societas civilis concerned the rights and responsibility of individuals towards the state and society, and were separate from government. In the present day, 'civil society' is a way to coordinate and to express the needs of public groups. Civil society helps to mark out problems and to offer solutions. Civil society organisations are the "third sector", ensuring the link between citizens and government and working as a counterbalance to the business sector.

In 2008, the European Commission's Directorate for Research Science, through its Science in Society Programme, held a seminar on the role of civil society organisations within research. The European Commission defines civil society organisation as "notfor-profit non-governmental organisations operating in the public interest" (1). They usually have a legal form, bring together people to act towards a shared goal and can include organisations concerned with advocacy, membership, public interest, service providers and professional organisations. The strength of civil society organisations is their variety of representing groups, interests and opinions. Civil society organisations hold values and principles of: work to the benefit of society, openness, accountability, tolerance, independent opinion, and a critical position. In the health field, the objectives of patient groups, which usually act for the interests of their members can be contrasted with public health CSOs which act more generally for the public good - although towards some defined aim.

Some information is known about the concerns for public health research of civil society organisations at European level. In 2006, Gulis et al. surveyed over 150 members that were identified in the database of the European Public Health Alliance (EPHA), 
itself a civil society organisation representing national member association interests at European level (2). Responses were gained from 80 organisations in 28 European countries, a response rate of $53 \%$. The majority $(80 \%)$ were working at national level, and were also members of international organisations. Their fields of interest included advocacy and networking (27\%), health promotion and human rights (22\%), provision of services $(20 \%)$, with smaller numbers including training (13\%), research 4 (9\%), campaigning (5\%), and provision of grants $(2 \%)$. Public health research needs were expressed across a wide range. Interestingly, there was little correlation between the CSOs' own stated aim and their proposed need for research, indicating that "CSOs do not focus on their own field only; they seem to be rather objective and independent" (2). There was also "a relatively high level of agreement" on themes for public health research priorities suggested by CSOs compared with the first call for public health research of European Commission's Seventh Framework Research Programme, and the Community Action Plan (3) for Public Health of the Directorate for Health and Consumer Protection - the two leading sources of European funding for health research and projects.

\section{Civil Society Organisations in STEPS}

STEPS (Strengthening Engagement in Public Health Research) was a project funded through competitive peer review by the European Commission's Science in Society Programme. The European Public Health Association (EUPHA), bringing together national public health associations, was a leading partner. National public health associations are civil society organisations, as they are not accountable to or directed by government but are voluntarily formed and independent organisations. Public health is a field with interests in common with civil society, as it also works on non-profit principles towards public benefit. The purpose of STEPS was to bring CSOs with an interest in public health broadly together, with a focus on public health research. STEPS took up the concerns and interests of the $12 \mathrm{EU}$ new member states because they have poorer health and less established research programmes than the 15 countries forming the EU before 2004.

Public health is concerned with the population's health through disease prevention, health promotion and the organisation of health services. Similarly, public health research addresses a wide range of subjects, both basic and applied, at the population level, and is often multi-disciplinary (4). It is undertaken in a range of settings including universities, health research institutes, public and private research organisations, and alongside public health practice. It complements biomedical research, which is concerned with the mechanisms of disease at molecular and cell levels, and clinical research on the treatment, rehabilitation and care of patients (5). The survey in STEPS was made to investigate the role of civil society organisations in public health research in the twelve new member states of the European Union, and the potential for collaboration between researchers and citizens to promote public health.

\section{METHODS}

CSOs were engaged in the two phased project. In the first phase collaborating country partners were identified, and these partners held national stakeholder workshops about the state of public health research in their countries. In the second phase, the results of the workshops were reviewed, the partners reported back to their national ministries of health and other stakeholders, and a final meeting for the project was held in Brussels (6).

In identifying a lead national partner in each country, the aim was to have a balance of both public health associations (representing the professional and researcher interests) and of other health-related civil society organisations. Sources for these national partner CSOs were initially national members of the European Public Health Association and of the European Public Health Alliance - both associations being members of the European Commission's coordinating mechanism for external consultation - the European Health Policy Forum (7). Finding the country-level partners was initially done through contacts, internet search and email, and then by a series of country visits made by the authors. At national level, listings of NGOs were also available in local languages.

The chosen country partners were brought together at a planning meeting held in Łodz, Poland, in November 2009. At this meeting, eight of the twelve partners decided that they would use a questionnaire to identify and learn from CSOs in their country, and also to promote the workshops that were to be held at national level. The topics of the questions were developed in four parts. The first part provided descriptive information of respondents; the second asked about the current organisation of public health research; the third part asked about collaboration in public health research, national and European; and the fourth part asked respondents to describe current important public health issues in the country and how they were being dealt with.

\section{Selection of Respondents}

One aim of the questionnaire was to identify potential participants for the national workshops. In Estonia, questionnaires were sent to 78 organisations that were believed to be engaged in issues related to public health. 21 completed questionnaires were returned, 9 organisations reported that they were not engaged in public health issues or research, 10 replies were from civil society organisations, 6 from governmental organisations, and 5 from research institutions. In Cyprus, the translated questionnaire was sent to 40 CSOs and professional associations in the south of the country. 25 questionnaires were sent by post and the rest by e-mail. There were 6 responses completed by CSOs and 7 by research organisations or professional bodies. In Latvia, the questionnaire was translated and sent to 25 CSOs by e-mail, 12 questionnaires (48\%) were sent back, while two of the remaining organisations replied that they were not going to complete the questionnaire because they did not wish to implement or use public health research. In Lithuania, the questionnaire was translated, and 18 were sent to departments of medicine, public health and social affairs at the major universities, state institutions responsible for certain aspects of public health, and NGOs that work on public health issues: 9 replies were received.

In Slovakia, the questionnaire was translated and sent to potential workshop participants selected from a national Registry of CSOs. Of 42 organisations identified, 9 organisations returned completed questionnaires, six replied that they did not wish to participate, 15 sent only confirmation they received the questionnaire and 12 did not reply. In Slovenia, the questionnaire was sent 
to civil society organisations only in the field of harmful alcohol drinking, because this was chosen for the national topic of the workshop. In Malta, the national partner sent the questionnaire in English to 26 organisations that were members of the Malta Health Network, and to 35 relevant health-related NGOs on the public list of the Commissioner for Voluntary Organisations (registered NGOs and Associations): 14 replies were received. In Romania, questionnaires were sent to 58 legally registered organisations with a mission or declared interest or current activity in public health, or were known to have published at national level, and which had an internet website with contact information about the organisation. 18 completed replies were received, from two professional organisations of physicians, 14 non-governmental organisations active in public health, one patients' organisation and one trading company. Table 1 shows the number of questionnaires sent, and those returned, by country and respondent. To review the responses, the questionnaires were each reviewed individually and responses were grouped under headings for analysis.

\section{RESULTS}

\section{Doing Public Health Research}

\section{Experience of Civil Society Organisations in Public Health Research}

In Estonia, civil society organisations that participated in the survey were engaged in advising, promoting healthy lifestyles, supplying information, training, implementing various preventive measures, and carrying out campaigns. Their experiences in relation to public health research were linked to the evaluation of health projects, and also to prevention studies, studies aimed at assessing the effect of different factors, and awareness studies. In Latvia, only a few CSOs had experience in public health research and do not consider their main objectives to include participation in research, for which they feel they lack resources of knowledge and human capacities. Some CSOs use information based on public health research by other research institutions or researchers; some are active in planning public health but not in research in public health policy. Most CSOs collaborate with other organisations in public health activities but only rarely in public health research.

In Slovenia, half of the organisations that responded to the survey said that they are not involved in any kind of research, for reasons including: lack of human resources, knowledge, or time; being too small; working in the rural areas rather than in the centre; and unwillingness to cooperate, since in their opinion, research is mostly done for research itself and rarely used in practice to improve the situation. Those responding positively on being involved in research were mostly applying research results and were to a lesser extent involved in undertaking research itself mainly dealing with social issues, and the organisational climate. In Slovakia, the majority of CSOs do not have direct experience in public health research, for reasons including lack of human capacities and orientation towards practice (e.g. educational or intervention programmes) rather than research. However, the League Against Cancer financially supports research by CSOs, for example, surveys on practice in tobacco control, and the national association of public health professionals has been involved in international research projects across fields including disabilities, health promotion and health indicators. In Romania most of the 14 organisations replying had been previously involved in research, particularly conducting knowledge, attitude and practice surveys.

\section{Quality of Research}

Estonia partners observed that data are more frequently collected in research than actually used. Malta participants suggested evaluation and monitoring once a service has been running to assess whether the service is meeting its target, who is making use of the service and what is its impact. They also advised conducting research not just for data collection and to carry out more action research and intervention studies with well defined objectives. They also sought implementation of sustainable services after EU projects are complete. Participants in Lithuania mentioned that the specific methodological grounds, representativeness and validity of research are not always given. They suggested NGOs should conduct research together with research institutes, to increase objectivity and professionalism, and that publishing research in reviewed journals would improve the research validity, Slovenian

Table 1. Numbers of surveys questionnaires sent and received back, by country

\begin{tabular}{|l|c|c|c|c|c|}
\hline \multirow{2}{*}{ Country } & \multirow{2}{*}{ Sent out } & \multicolumn{4}{|c|}{ Received } \\
\cline { 3 - 6 } & & Total & CSOs & Government & Research \\
\hline Estonia & 78 & 21 & 10 & 6 & 0 \\
\hline Cyprus & 40 & 13 & 12 & 0 & 7 \\
\hline Latvia & 25 & 12 & - & - & 0 \\
\hline Lithuania & 18 & 9 & 14 & 0 & 0 \\
\hline Malta & 61 & 18 & 9 & 0 & 0 \\
\hline Romania & 58 & 9 & 32 & 0 & 0 \\
\hline Slovakia & 42 & 32 & 98 & 6 & 0 \\
\hline Slovenia & 150 & 128 & & & 0 \\
\hline & 472 & & & \\
\hline
\end{tabular}


participants considered that CSOs should pay attention to ethical aspects of the research process and be concerned with potential abuse of private information for research purposes, e.g. by local societies working with weaker sections of the population.

\section{Public Health Research Policy}

\section{Experience in Public Health Research Policy and Planning}

In Estonia, civil society organisations have participated in association with research institutions in policy groups with the Ministry of Social Affairs, engaged with politicians and political parties on public health, the development of legislation and draft legislation, and the development of plans for healthcare. In Slovenia, $12 \%$ of organisations reported being members of working groups at the Ministry of Health and the Ministry of Labour, Family and Social Affairs. In Romania, 7 of 16 organisations stated they participated, to some extent, in the healthcare planning process, but not in the public health research planning, mainly because there is no formal consultation framework.

\section{Setting up the Priorities and Policy}

Participants in Lithuania were unclear what/how much public health research is commissioned by state institutions for the purpose of specific policy decisions, and recommended this as a relevant area for analysis and to commission studies. In Slovenia, participants stated that CSOs were rarely included in the decision making on research priorities, even though research is required through the civil society. In Malta and Slovenia, participants proposed that CSOs should contribute to the determination of priorities for public health research - for these to be representative of different groups in society, and to enable CSOs to provide advice in the transfer of research results back into the community. Malta participants recommended a political statement on the need for public health research to balance general state policy, a national strategy for public health research, and specific funding, within the broader national research and innovation strategy.

\section{Collaboration}

Participants in all countries expressed need for collaboration between CSOs, professional organisations and governmental institutions. In Slovakia participants mentioned collaboration at regional as well as local levels. In Latvia, participants described the need for consultations with public groups on further public health research actions. In Estonia and Slovenia, participants suggested that there should be, at least annually, an information day and seminar to discuss both future studies, data needs, and also review existing and completed studies. The Latvian Public Health Association proposed inviting CSOs to their meetings where the results of different researches are presented. Participants in Malta stressed that NGOs should be engaged with research projects at the outset, and thereafter, in regular consultations through the University of Malta, while in Cyprus, the Ministry of Health could give support to the participation of CSOs.

\section{Coordination of Public Health Research Policy}

Participants in Lithuania described need for better coordination of public health research, suggesting that the potential institution could be the Research Council of Lithuania or the National Health Council under the Parliament. They suggested that the Research Council of Lithuania should appoint a coordinator for public health research in relation to the National Health Council, the institution accountable to the Parliament. Participants in Slovenia suggested building an information system about projects, new research and new prevention programmes, and recommended the internet portal MOSA of the National Research Council. Participants in Malta suggested a network for public health research to develop, implement and disseminate ideas and news within partnerships. They also proposed a task force on public health research as a part of the Malta Health Network and a sub-committee of experts to train and advise the NGO members of the health network. Slovakia participants proposed a national database of all organisations (CSOs, professional organisations) interesting in and/or working in the field of public health research.

\section{CSO Capacities in Public Health Research}

\section{CSOs as Advocacy Tool}

While participants in several countries debated that CSOs are not able to do specific research work, nevertheless, proposed that CSOs could serve as lobby tool and resourse for spreading information. In Lithuania NGOs can promote cooperation in organising, conducting and publicising public health research. In Malta, NGOs should 'sell themselves' better and lobby with government entities and other organisations to be involved in research projects, particularly projects which bridge the gap between policy and practice. Romanian participants suggested that all CSOs have a potential role in research - mobilizing researchers and organisations, supporting research themes, and lobbying for evidence-based policy and decision-making. In Slovenia, participants said that civil society organisations in the area of alcohol are already mostly involved in using research data to meet their goals, exchanging knowledge and transferring research results (evidence) to the community level.

\section{Building up Capacity of CSOs}

Participants in Romania proposed that CSOs should learn how to use EU opportunities and participate in projects, how to select and filter the existing information (which is extensive), and how to become a part of EU projects, especially but not exclusively in the research area. Slovenia participants suggested increasing education for CSOs on evaluation, use of different research methods, advocacy, ethical principles in research, and ways of translating knowledge into practice. The Latvian Public Health Association (LPHA) proposed seminars on research methods for CSOs. In Malta, participants suggested to set up and maintain an inventory of NGOs and other organisations with research expertise. In Slovakia, participants encouraged CSOs in capacity building for public health research through cooperation with professionals in the field. In Cyprus, participants advised that CSOs need stronger 
incentives in order to participate in research. In Latvia, meetings with experts could help raise funds for research to implement a research project, and help with their interpretation. In Lithuania, there is a lack of funding for public health research specifically, and it is difficult for civil society organisations to compete with governmental institutions for research funds. Competition with governmental institutions is not fair and transparent, for example in lack of co-financing of European projects. Malta has taken active steps to make NGOs aware of funding opportunities and to create a system to help NGOs to apply for such funds. Further action could include NGOs joining together to pay the salary of a full time experienced person, who would fill in applications on their behalf.

\section{Fundraising for Public Health Research}

Civil society organisations received their funding for public health research from voluntary donations, the Open Society Foundation, the Ministry of Social Affairs, the National Health Insurance Fund, the Gambling Tax Council, local governments, the private sector, and the Global Fund to Fight AIDS, Tuberculosis, and Malaria. State institutions have financed public health research with money from the state budget as well as resources provided by European funds, the World Health Organization, and the Health Insurance Fund. Research institutions have received funding for public health studies from grants and sources made available by both the state and the EU. The projects of civil society organisations are generally funded on a case-by-case or contractual basis.

The main challenge for Estonian civil society organisations in relation to funding is their own contribution requirement, which they find difficult to fulfil. Secondly, sometimes it is difficult to spend the budgeted means (some costs are overestimated or underestimated in comparison to national conditions). The challenges mentioned by the organisations also included preparing projects, conducting surveys, and writing reports. The main challenges reported by state institutions included improving their administrative capability and developing their information systems as well as budget constraints, the lack of workforce, and the organisation of public procurements. In Slovakia, public health research activities have been funded mostly from the European sources (including DG SANCO, DG Research, WHO Country Office), and partly from national public or private sources (including sponsorship). Two thirds of the organisations in Slovenia responding to the survey do not apply for research tenders, for reasons including lack of research and expert administrative staff, lack of own resources, low awareness of current tenders and lack of knowledge to plan and carry out research. Yet, those CSOs that do apply for research tenders are in the majority of cases successful in aquiring funding, from local municipalities, the Ministry of Health and the Ministry of Labour, Family and Social Affairs.

\section{DISCUSSION}

\section{The Surveys}

The eight national surveys reported here were primarily designed to identify civil society organisations which could be interested in participating in the STEPS country workshops (8, 9). The national organisations undertaking the surveys differed one from another in tradition and cultural approaches. The CSOs had to have sufficient interest in the subject to respond, and the results have been extracted in a two-stage process - reporting by the national partner and then synthesis of these reports. The responses from the countries are not fully representative, and depend on the frameworks used by each national partner to identify CSOs. The survey also revealed differences among countries: geographically smaller countries such Cyprus and Malta identified similar numbers of civil society organisations as larger countries.

Civil society organisations are active in all the reporting countries. They have an interest and experience in research related to public health - or more generally in the social field - and they seek continued and greater engagement. The majority of CSOs replying were themselves not involved directly in research, for lack of relevance to their objectives or sometimes for lack of knowledge and human resources, although a minority described contributing to research particularly collecting information on needs and services. But the CSOs were interested to work with research organisations and institutes to raise quality of the research on both sides. There is also a thirst for information from research - it can help set agendas for civil society action, and can help contribute to innovation in service delivery and access for diverse members of society. Moreover, there was a desire for better communication and dissemination about research, both results from completed research and earlier involvement on forthcoming projects. Methods for dissemination using networks and electronic communication need to be developed, both at national levels using national languages and also European-wide for comparison and extending the European Research Area.

\section{Role of Not-for-profit Organisations}

The descriptions from 128 civil society organisations in 8 EU new member states of their engagement with public health research provides a valuable understanding of the place of these organisations in their country's research programmes and indeed, in European research. In general, science, technology and research is considered a responsibility of the state, partly because the costs can be high (e.g. for technological research) and partly because the knowledge itself (e.g. in electronics or defence) may be of great value to the state itself, partly because research is regarded as a not-for-profit field, partly because it is usually undertaken in public education institutions. But the European Union proposes to raise the proportion of GNP spent on research up to $3 \%$ and to create a European as a 'knowledge-based economy'. To gain these funds, the EU seeks to expand the contribution of industry - and particularly small and medium enterprises - to research and innovation, drawing on evidence that successful 'future' economies depend on innovation and tecnical expertise.

Yet, the not-for-profit sectors of society have not been sufficiently considered in this debate. Economies are not only commercial enterprise: the public sector is responsible for one up to two thirds of economic activity in all European countries, and issues of innovation, efficiency and competitiveness are as important for public sector 'markets' as they are for the private sector - and need as much stewardship. European research has been criticised in giving undue emphasis to commercial interests 
(10). Civil society organisations have the potential as the 'third sector' to provide innovation and also value-for-money. In some of the social fields of public health, such as drugs and AIDS prevention, and elderly and disability services, civil society organisations are already partners with researchers for the better delivery of services to specific patient groups. In advocacy fields there are needs for policy research which non-governmental organisations may be best placed to lead because of their indendent and noncommercial character.

\section{Involvement in Research}

Should CSOs be involved directly in research? Civil society organisations in the surveys drew attention to the lack of capacity for directly undertaking research themselves. Partnerships between CSOs and academic institutions have been recommended in the field of HIV/AIDS: such partnerships can both help CSOs validate and measure the impact of their work, and help them to get technical assistance for their projects, while academic institutions can get easier access to community networks and can better train their staff and students to solve real public health problems (11). A study in the field of drug misuse saw three different positions for researchers in community intervention studies: first, acting as an independent observer and evaluator of project outcomes, second, providing scientific advice, including training and technical assistance; and third, providing research design in partnership with the practitioners (12). The perspective of European health civil society organisations was that they valued contact with researchers, including developing objectives and disseminating results, but saw the actual practice of research as the domain of the (social) scientists. The social fields of health, where CSOs have led practice in recent years, are more likely arenas for contributing to research than in larger epidemiological studies investigating characteristics of individuals in populations. Nevertheless, it is possible that CSO participation would improve the validity of measures in public health research as well as completeness of sampling, providing commentary on results, and assisting in developing impact - all concerns for improving the quality of research.

\section{European Contribution}

The involvement of civil society organisations in Europe has risen in recent years. Writing in 2003, before European Union enlargement was completed, Banthien et al. (13) suggested that political engagement with CSOs can improve accountability in decision-making, legitimacy and acceptance of decisions, build trust between stakeholders, and raise public awareness on scientific issues. They also described regional differences across Europe: northern countries viewed engagement as a means to move from consultation to dialogue; southern countries viewed CSO participation as a challenge to 'normal' politics; and in CEE countries, CSOs were a counter to the new conditions of poorly-regulated markets. In anticipation of the (then proposed) Seventh Framework Research Programme, Claudia Neubauer for the Fondation Sciences Citoyennes (14) argued for greater consultation with civil society organisations and more attention to the 'social' area in the research agenda. In our survey in 2010 in the new member states, there was a sense of greater maturity in the roles for CSOs. This is partly through the stabilisation of economies and political processes, and partly through systematic organisation of CSOs, e.g. with national registers, legal arrangements for donations, and councils for voluntary services, which provide a more stable framework for their activities. In this setting, further engagement in research seems a realistic development.

The findings in this study complement those of a recent survey on research with CSOs at European level (15). The European Union can support this development financially in the new member states through programmes within the Structural Funds as well as directly through the Directorate for Research, and allied European organisations (including civil society organisations) can contribute in dissemination of knowledge and providing opportunities for transnational sharing and debate. Civil society organisations also have an important role in providing a balance to the strong influence of the pharmaceutical industry in orienting medical practice towards treatment rather than prevention, and for-profit rather than socially-oriented activities (5). Although the scales are, of course, unequal in financial terms, the contribution of CSOs to research in areas of health policy such as tobacco and alcohol, AIDS, and social care is highly significant for the 'European social model', and requires fostering, support and development.

\section{CONCLUSION}

Civil society organisations are an important 'third sector' between government and business, with a not-for-profit orientation that fits with the objectives of research. Although the different perspectives between countries may in part be related to different sampling frameworks and response rates, there was interest in public health research in all eight countries.

Some, though not all, CSOs are interested in developing capacities for public health research and using the results for better practice. Further knowledge could come through more in-depth studies and examples of good practice. Research commissioning organisations could seek greater involvement of CSOs in setting priorities for public health research, and both researchers and governmental institutions can gain through dialogue with CSOs on the results of research and the implications for public health policy.

\section{Acknowledgements}

We are grateful to lead partners in STEPS in the eight countries for gathering this information.

\section{Funding}

The research in STEPS leading to these results has received funding from the European Union's Seventh Framework Programme (Science in Society) under grant agreement 217605.

\section{Conflict of interest}

None declared

\section{REFERENCES}

1. Fazi E, Smith J. Civil dialogue: making it work better. Brussels: Civil Society Contact Group; 2006.

2. Gulis G, Garrido-Herrero L, Katreniakova Z, Harvey G, McCarthy M; Slovak Public Health Association. Public health research priorities in Europe seen by non-governmental organizations. Cent Eur J Public Health. 2008 Dec;16(4):209-12. 
3. Public health. Programme of Community action in the field of public health (2003-2008) [Internet]. Brussels: European Commission [cited 2012 Oct 23]. Available from: http://collection.europarchive.org/ dnb/20070702132253/ec.europa.eu/health/ph_programme/programme en.htm.

4. McCarthy M, Clarke A. European public health research literatures: measuring progress. Eur J Public Health. 2007;17 Suppl 1:2-5.

5. McCarthy M. Who supports health research in Europe? Eur J Public Health. 2010 Feb;20(1):3-5.

6. STEPS (Strengthening Engagement in Public Health Research). Public health research in Europe [Internet]. [cited 2012 Oct 23]. Available from: http://www.steps-ph.eu/.

7. European Commission. Public health. EU health policy forum [Internet]. Brussels: European Commission; 2012 [cited 2012 Oct 23]. Available from: http://ec.europa.eu/health/interest_groups/eu_health_forum/ policy forum/index en.htm.

8. STEPS (Strengthening Engagement in Public Health Research). Country workshop reports [Internet]. [cited 2012 Oct 23]. Available from: http:/ www.steps-ph.eu/country-workshop-reports/.

9. McCarthy M. STEPS report: public health research - Europe's future. London: University College London; 2011.

10. Fondation Sciences Citoyennes. Public research should benefit society, not big business: an open letter on the Common Strategic Framework for EU Research and Innovation Funding [Internet]. [cited 2012 Oct 23]. Available from: http://sciencescitoyennes.org/open-letter-eu-research/.

11. Mora JC, Purohit A, Haag A, Warren D, Garg D, Harsh J. The public health role of non-governmental organizations (NGOs) working on HIV/AIDS issues. XIV International AIDS Conference. 2002 Jul 7-12; Barcelona, Spain. Boston: US Foundation; 2002.

12. Holmila M, Holder H, Andreasson S, Baklien B, Rossow I: Roles for researchers in community action projects to prevent alcohol and other drug problems: methodological choices. Drugs. 2008,15(4):410-23.

13. Banthien H, Jaspers M, Renner A. Governance of the European research area: the role of civil society. Bensheim: IFOK; 2003.

14. European Public Health Alliance. What role for civil society in research? [Internet]. Brussels: EPHA; 2006 [cited 2012 Oct 23]. Available from http://www.epha.org/a/2064.

15. Beinare D, McCarthy M. Civil society organisations, social innovation and health research in Europe. Eur J Public Health. In Press.

Received January 25, 2012 Accepted in revised form September 21, 2012 